\title{
WOUND HEALING EFFECT OF NARINGIN GEL IN ALLOXAN INDUCED DIABETIC MICE
}

\author{
ALLOKSAN ILE DIYYBET OLUŞTURULMUŞ FARELERDE NARINGIIN JELIN YARA \\ IYILESTIRICCI ETKILLRE
}

\section{Mehmet Evren OKUR ${ }^{1, *}$, Ayşe Arzu ŞAKUL ${ }^{2}$, Sule AYLA ${ }^{3}$, Ayşe Esra KARADA $\breve{G}^{4,5}$, Cemre Şahin ŞENYÜZ ${ }^{6}$, Şebnem BATUR ${ }^{7}$, Benay DAYLAN ${ }^{3}$, Ekrem Musa ÖZDEMİR ${ }^{8}$, Sezin PALABIYIK-YÜCELIK ${ }^{9}$, Hande SIPPAHI' ${ }^{6}$, Ahmet AYDIN ${ }^{6}$}

${ }^{1}$ University of Health Sciences, Faculty of Pharmacy, Dept. of Pharmacology, Istanbul, Turkey ${ }^{2}$ Istanbul Medipol University, School of Medicine, Dept. of Medical Pharmacology, Istanbul, Turkey ${ }^{3}$ Istanbul Medipol University, School of Medicine, Dept. of Histology and Embryology, Istanbul, Turkey

${ }^{4}$ Istanbul Medipol University, School of Pharmacy, Dept. of Pharmacognosy, Istanbul, Turkey

${ }^{5}$ Anadolu University, Graduate School of Health Sciences, Dept. of Pharmacognosy, Eskişehir, Turkey

${ }^{6}$ Yeditepe University, Faculty of Pharmacy, Dept. of Pharmaceutic Toxicology, Istanbul, Turkey

${ }^{7}$ Istanbul University, Cerrahpasa, Faculty of Medicine, Dept. of Clinical Pathology, Istanbul, Turkey

${ }^{8}$ Istanbul Medipol University, Dept. of Animal Facility, Istanbul, Turkey

${ }^{9}$ Atatürk University, Faculty of Pharmacy, Dept. of Pharmaceutic Toxicology, Erzurum, Turkey

\section{ABSTRACT}

Objective: The aim of this study was to investigate the effects of naringin, a known flavonoid, on in vitro cytotoxicity, irritation and in vivo potential efficacy when topically applied to the diabetic wound.

Material and Method: In vitro direct contact assay and hen's egg chorio-allantoin membrane tests were used to evaluate irritation, and cytotoxicity potential of Naringin. In vitro antimicrobial activity was also tested. Topical treatments were administered once a day on the wound. Wound lesions were photographed and statistically analyzed. After the 10th day, histopathological parameters of tissues were assessed.

\footnotetext{
* Corresponding Author/Sorumlu Yazar: Mehmet Evren Okur e-mail / e-posta: evrenokurecz@gmail.com, Phone / Tel.: +902164189616
} 
Result and Discussion: The results showed that naringin gel has no cytotoxicity and irritation potential. Also, it displayed a weak antimicrobial effect. Aside from these, in vivo studies revealed that naringin gel showed statistically higher wound contraction and re-epithelialization, the thickness of granulation tissue, angiogenesis scores. The results indicated that naringin gel effectively enhanced diabetic wound healing, and so this formulation could be considered a promising therapeutic alternative for treating diabetic wounds.

Keywords: Cell culture, Diabetes mellitus, HET-CAM, Naringin, Wound healing

\section{ÖZ}

Amaç: Bu çalışmanın amacı, bir flavonoid olan Naringin'in in vitro sitotoksisite, irritasyon ile diyabetik yara üzerindeki in vivo potansiyel etkilerini araştırmaktı.

Gereç ve Yöntem: Naringin'in irritasyon ve sitotoksisite potansiyelini değerlendirmek için in vitro doğrudan temas deneyi ve tavuk yumurtası korio-allantoin membran testleri kullanıldı. Aynı zamanda in vitro antimikrobiyal etkinlikte test edildi. Topikal tedaviler günde bir kez yaraya uygulandi. Yara lezyonları fotoğrafland ve istatistiksel olarak analiz edildi. 10. günden sonra dokuların histopatolojik parametreleri değerlendirildi.

Sonuç ve Tartışma: Sonuçlar, naringin jelin sitotoksisite ve tahriş potansiyeli olmadığını göstermiştir. Ayrıca, zaylf bir antimikrobiyal etki gösterdi. Bunların yanı sıra, in vivo çalışmalar naringin jelin istatistiksel olarak daha yüksek yara kapanması ve re-epitelyalizasyon, granülasyon dokusunun kalınlı̆̆l ve anjiyogenez skorları gösterdiğini ortaya koymuştur. Sonuçlar, naringin jelin diyabetik yara iyileşmesini etkili bir şekilde arttırdığını gösterdi ve bu nedenle bu formülasyon, diyabetik yaraların tedavisi için umut verici bir terapötik alternatif olarak düşünülebilir.

Anahtar Kelimeler: Diabetes mellitus, HET-CAM, Hücre kültürü, Naringin, Yara iyileşmesi

\section{INTRODUCTION}

Diabetes mellitus (DM) is a metabolic disorder characterized by hyperglycemia over a prolonged period [1]. The majority of DM-related complications occur and are separated into macrovascular (cardiovascular disease) and microvascular (retinopathy, nephropathy, and neuropathy) complications [2].

Delayed wound healing and nonhealing ulcers (especially foot ulcers) are mainly caused by DM; more than $50 \%$ of these wounds become infected and require hospitalization [3]. Previous reports suggested that most of the nontraumatic lower extremity amputations are related to diabetes complications. Moreover, nearly half of the total cost of diabetes care is spent on the management of diabetes-related wounds. It is claimed that an excess of the United States (US) \$25 billion is spent annually on the treatment of chronic wounds [4].

Physiological wound healing is a complex, finely balanced process that is generally thought to comprise four interconnected and overlapping stages: haemostasis (clot formation), inflammation, proliferation, and remodeling [5]. The wound healing process involves a variety of specialized cells such as platelets, macrophages, fibroblasts, epithelial and endothelial cells. The platelets have a key role in primary hemostasis. It is followed by the neutrophils, leading to the inflammatory phase and later taken over by the macrophages [6]. 
In diabetic patients, the healing process is stalled in the inflammatory phase that is manifested by the upregulation of proinflammatory cytokines, proteases, and reactive oxygen species (ROS), as well as cellular dysfunctions. Wound healing impairment in diabetic patients is associated with decreased levels of various growth factors such as vascular endothelial growth factor (VEGF), epidermal growth factor (EGF), platelet-derived growth factor (PDGF), transforming growth factor-b (TGF-b), or impaired collagen deposition and delayed inflammatory response [5].

Diabetics have impaired leukocyte function, and the metabolic abnormalities of diabetes lead to inadequate migration of neutrophils and macrophages to the wound, along with reduced chemotaxis. Due to these cellular changes, diabetic wounds are more prone to infection [7,8]. Diabetic foot ulcer patients have severe neuropathy, elevated leucocyte counts, and lower endothelium-dependent and independent vasodilation in the macro-circulation. These events decrease the cellular and growth factor responses, diminish the peripheral blood flow and local angiogenesis [6].

Standard treatments for diabetic wounds include debridement of necrotic tissue, revascularization surgery, infection control, mechanical offloading, control of blood glucose, foot care education, and limb elevation. However, these treatments are often insufficient to ensure satisfactory wound healing and are associated with high rates of limb amputation [9]. Therefore, alternative therapies are urgently needed to shorten the process of healing diabetic wounds using animal models.

The wound healing effect of several medicinal plants and/or plant-derived substances such as phenolic compounds have been investigated. More than $70 \%$ of wound healing pharmaceutical products are derived from plants, $20 \%$ are mineral based and the remaining are animal-derived products. Flavonoids are phenolic substances isolated from a wide range of vascular plants, with over 8000 individual compounds known and these compounds possess several biological activities such as antimicrobial, anti-inflammatory, antioxidant, and antidiabetic [10,11].

Naringin (4',5,7-trihydroxy flavanone 7-rhamnoglucoside) (Fig.1) is a major and active flavanone glycoside, isolated from the grape and citrus fruit species, which has been shown to have several pharmacological properties such as neuroprotective, hepatoprotective, antimicrobial, cardioprotective, anti-inflammatory, antioxidant, and renoprotective effects [12].

Hence, the main purpose of the current study was to enlighten the therapeutic ability of Naringin loaded gel with an excision wound model by evaluating several macroscopic and histological parameters in alloxan induced diabetic mice. On the other hand, in vitro alternative approaches for the assessment of safety and biocompatibility of novel formulations are of great importance. Therefore, cytotoxicity and irritation potential of Naringin loaded gel was evaluated using direct contact assay and hen's egg chorio-allantoin membrane (HET-CAM) test method. 


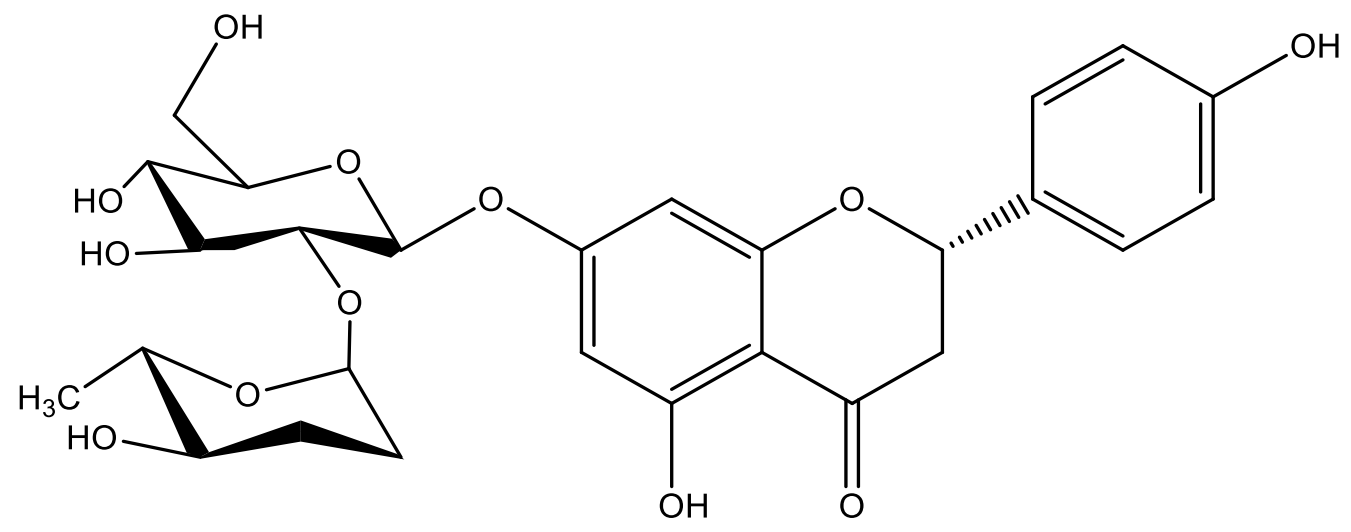

Figure 1. The chemical structure of Naringin

\section{MATERIAL AND METHOD}

\section{Materials}

Staphylococcus aureus ATCC 6538, Candida albicans ATCC 64548, Listeria monocytogenes ATCC 35152, and L929 healthy mouse fibroblast cell strains were purchased from American Type Culture Collection (ATCC, USA). Alloxan, Naringin, hydroxyethyl cellulose, and isopropanol were purchased from Sigma (Germany) and DMEM was purchased from Gibco (USA). All other reagents used in this study were of analytical or HPLC grade.

\section{Preparation of topical extract gel}

The base gel was composed of $2 \%$ hydroxyethyl cellulose. Firstly, $2 \mathrm{~g}$ hydroxyethyl cellulose was dispersed in distilled water by slowly stirring using a mechanical stirrer, at room temperature. Distilled water was added to the mixture slowly and the final weight of the mixture was completed to $100 \mathrm{~g}$. Following, the blend was stirred constantly until the formation of a clear gel is observed. Then, Naringin gel $(5 \%, w / w)$ was formulated by mixing base gel in a 95:5 ratio with Naringin by stirring gently.

\section{In vitro Biological Assays}

\section{Antimicrobial activity}

The in vitro antimicrobial activity was evaluated by determining the minimum inhibitory concentration (MIC) via the broth microdilution method recommended by the Clinical and Laboratory Standards Institute (CLSI) [13]. The commonly found microorganisms on colonized wounds were studied; S. aureus ATCC 6538, Escherichia coli NRLL B-3008, L. monocytogenes ATCC 35152 and 
C. albicans ATCC 64548 strains were grown in Mueller Hinton Broth (MHB, Merck, Germany); C. albicans species were grown in RPMI broth for $24 \mathrm{~h}$ at $37^{\circ} \mathrm{C}$ in aerobic conditions. The bacterial suspension was adjusted to match $0.5 \mathrm{McFarland}$ turbidity standards (corresponding to $10^{8}$ colony forming unit $(\mathrm{CFU}) / \mathrm{mL})$ with sterile saline [14].

\section{Cytotoxicity measurement by direct contact assay}

A direct contact test that allows measuring quantitative evaluation of cytotoxicity was performed according to the International Organization of Standardization (ISO) recommended protocol [15]. L929 cell was cultured in DMEM supplemented with 10\% FBS and 1\% penicillin (10.000 units $/ \mathrm{mL})$ and streptomycin $(10.000 \mu \mathrm{g} / \mathrm{mL})$ at $37^{\circ} \mathrm{C}$ under a humidified atmosphere of $5 \% \mathrm{CO}_{2}$ [16]. The $\mathrm{L} 929$ cell is plated in a 24-well culture dish and incubated until it forms a semi-confluent layer for 24 hours. Then, for direct contact, positive control (4\% SDS), negative control (PBS), Naringin gel and were applied to the filter papers with a pore size of $0.45 \mu \mathrm{m}$ and were placed into the wells on the cell surface. The filter papers were prepared in sizes corresponding to the 1:10 of the surface of the well are and sterilized. After $24 \mathrm{~h}$, cell medium and filter paper were discarded. MTT solution $(0.5 \mathrm{mg} / \mathrm{mL})$ was added to wells and cells were incubated $\left(37^{\circ} \mathrm{C}\right)$ for a further $2 \mathrm{~h}$. At the end of the incubation period, the cell culture medium was removed and $100 \mu \mathrm{L}$ of isopropanol was added into each well for dissolving the formazan. The optical density (OD) was determined at $570 \mathrm{~nm}$ using an ELISA microplate reader (BioTek, USA). The reduction in viability compared to negative control is calculated using the equation below.

$$
\text { Cell viability }(\%)=\left(\mathrm{OD}_{570}(\text { sample }) \times 100\right) / \mathrm{OD}_{570(\text { negative control })}
$$

\section{Hen's Egg Chorio-Allantoin Membrane Test}

For the assessment of the irritation capability of the formulation, the HET-CAM assay was conducted according to the Interagency Coordinating Committee on the Validation of Alternative Methods (ICCVAM) [17]. The test system consists of fresh, clean, and fertile White Leghorn chicken eggs (50-60 g). Eggs are candled to detect the viability and development of embryo's prior to use and nonviable or defective eggs are eliminated. Eggs were placed in an incubator with a rotating tray and were incubated at $38 \pm 0.2^{\circ} \mathrm{C}$ and $58 \pm 2 \%$ relative humidity.

On day 9, eggs were removed from the incubator and the air cells of the eggs were marked and eggs were cut from the marked sections via a rotating saw blade and pared off. After moistening with $0.9 \% \mathrm{NaCl}$, eggs were placed into the incubator for up to $30 \mathrm{~min}$. Afterward, $0.9 \% \mathrm{NaCl}$ solution was decanted from the eggs. The egg white membrane was removed while avoiding any damage to the fine blood vessels. $0.3 \mathrm{~mL}$ of test substances, $0.9 \% \mathrm{NaCl}$ (negative control; $\mathrm{NC}$ ), and $0.1 \mathrm{~N} \mathrm{NaOH}$ (positive 
control; PC) were directly applied to the chorioallantoic membrane (CAM) surface and allowed in contact for 300 seconds. Monitored and recorded the time for the appearance of each of the noted endpoints in seconds.

The ICCVAM recommended irritation score (IS) analysis method was used for the evaluation. This method is based on the development of the three HET-CAM endpoints at fixed time intervals of 0.5, 2, and $5 \mathrm{~min}$. By summing up the numerical time-dependent scores for lysis (blood vessel disintegration), hemorrhage (bleeding from the vessels), and coagulation (intra- and extra-vascular protein denaturation), a single numerical value is obtained with a maximum value of 21 (Table 1).

Table 1. Scoring scheme for irritation testing with the HET-CAM test method

\begin{tabular}{|c|c|c|c|}
\hline \multirow{2}{*}{ Effect } & \multicolumn{3}{|c|}{ Score } \\
\cline { 2 - 4 } & $\mathbf{0 . 5}$ Min & 2 Min & 5 Min \\
\hline Lysis & 5 & 3 & 1 \\
\hline Hemorrhage & 7 & 5 & 3 \\
\hline Coagulation & 9 & 7 & 5 \\
\hline
\end{tabular}

If the non-irritant response with $\mathrm{NC}$ and a severe irritant response with $\mathrm{PC}$ are monitored respectively, then the irritation test is considered acceptable. According to historical control studies, the IS value of negative control $(0.9 \% \mathrm{NaCl})$ was 0.0 , and the IS value of positive controls (1\% SDS and $0.1 \mathrm{NaOH}$ ) ranged between 10 and 19, respectively. When using the IS analysis method, the severe irritancy classification for a test substance is assigned for values greater than nine.

\section{In vivo Experiments}

\section{Test animals}

The balb-c mice (26-30 g) were kept in standard cages and maintained in a climate room under controlled conditions of temperature $\left(23 \pm 2^{\circ} \mathrm{C}\right)$, relative humidity $(50 \pm 10 \%)$, with an inverted $12 \mathrm{~h}$ light: dark cycle (lights off at 8 a.m.) and they had access to standard nutritionally balanced diet and tap water ad libitum.

In this study, all animal procedures were in strict accordance with the guidelines of the European Council Directive (EU2010/63). All experiment procedures and protocols used in the study were reviewed and approved by the Ethics Committee of Istanbul Medipol University (No:38828770604.01.01-E.66328) in accordance with the Standards for the Care and Use of Laboratory Animal. 


\section{Induction of diabetes mellitus}

DM was induced by intraperitoneal (i.p.) injection of freshly prepared alloxan $(150 \mathrm{mg} / \mathrm{kg}) \mathrm{after}$ overnight (12 hours) fasting of mice. Alloxan was applied in an isotonic saline solution three times over a 48-hour period. Diabetic mice were confirmed by the fasting blood glucose concentration above 200 $\mathrm{mg} / \mathrm{mL}$ on the $7^{\text {th }}$ day after alloxan administration [18].

\section{Experimental wounding and treatment}

The animals were divided into the following 4 groups at random $(n=7)$; Untreated (as control), Blank gel (as a vehicle), Naringin gel, Madecassol ${ }^{\circledR}$ (Bayer, Switzerland) (as standard). The mice were anesthetized with a single i.p. injection of Ketamine/Xylazine $(100 / 10 \mathrm{mg} / \mathrm{kg})$, after dorsal hair was removed with an electric razor, and the exposed skin area was cleaned with a povidone-iodine solution. Then, circular full-thickness wounds were made bilaterally on the back of each animal by a $5 \mathrm{~mm}$ punch biopsy. All treatments were conducted once a day and lasted for 10 days [19].

\section{Macroscopic wound healing assessment}

The day when wounds were made was designated as day 0 , the process of wound healing was observed from then until day 10 after wounding. On days 0,6 , and 10 after the operation, the wounds were photographed with a digital camera (Canon, Japan). The wound area was measured using ImageJ (National Institutes of Health, Bethesda, MD, USA), and wound contraction rate was calculated by the following equation:

$$
\% \text { Wound contraction }=\left(\text { Wound } \text { Area }_{\text {actual }} / \text { Wound Area } \text { initial }\right) \text { X } 100
$$

\section{Histology}

Mice were sacrificed on the $10^{\text {th }}$ day and the whole wound with a margin of around $5 \mathrm{~mm}$ of ambient unwounded skin was excised for histological evaluation. All samples were fixed in $10 \%$ neutral formalin. After $24 \mathrm{~h}$, the biopsies were bisected, embedded in paraffin, and sectioned in $5 \mu \mathrm{m}$ thick layers. The $5 \mu \mathrm{m}$ thick sections were mounted on glass slides, dewaxed, rehydrated with distilled water, and stained with hematoxylin-eosin (HE) to be evaluated via light microscopy.

Wound healing rates of each group was assessed by the ranking method defined by Galeano et al. [20]. Epidermal and dermal regeneration score system was; 1 : Epidermal formation (poor) $\geq 20 \%$; 2 : Epidermal formation (incomplete) $\geq 40 \% ; 3$ : Epithelial proliferation (moderate) $\geq 60 \%$; : Epidermal remodelling (complete) $\geq 80 \%$. Score system of the granulation tissue thickness was; 4 : very thick layer; 3: thick layer; 2: moderate layer; 1: thin layer. 
The angiogenesis was evaluated by counting and identifying only mature vessels the existence of erythrocytes in the lumen. The presence/absence of edema, thrombosis, hemorrhage, congestion, and intra/intervascular fibrin formation was evaluated to identify poorly formed and well-formed capillary vessels. Score system of angiogenesis was; 1: High level of hemorrhage, edema, occasional congestion, and thrombosis; 2: Capillary vessels (newly formed, 3-4/site), occasional congestion, moderate edema and hemorrhage, intravascular fibrin deposition and absence of thrombosis; 3: Capillary vessels (newly formed, 5-6/site); 4: Capillary vessels (newly formed and normal appearing, >7/site).

\section{Statistical analysis}

Results were given as means \pm standard error of the mean (Mean $\pm \mathrm{SEM}$ ). Statistical analyses were evaluated with GraphPad Prism 7.0 program. Statistical significance between groups was analyzed by one-way ANOVA. Values for $\mathrm{p}<0.05$ were considered statistically significant.

\section{RESULT AND DISCUSSION}

\section{Antimicrobial Activity}

Various studies have demonstrated that the antimicrobial effects of various plant extracts have been attributed to their flavonoid contents [21]. Flavonoids are oxygen-containing aromatic compounds in which their wound healing properties are well known. These compounds can promote rapid wound healing due to their antimicrobial, antioxidant, and astringent properties [22].

In this study, the antimicrobial activity of the naringin was tested against various human pathogenic microorganisms such as E. coli, S. aureus, L. monocyt, and C. albicans. Table 1 shows the antimicrobial activity of naringin. Naringin showed weak antimicrobial activity against the tested microorganisms as compared to Amoxicillin and Ketoconazole. However, a MIC value of naringin of $31.2 \mu \mathrm{g} / \mathrm{mL}$ against $S$. aureus was determined (Table 2). S. Aureus has been reported as a common pathogen found on chronic wounds as diabetic wounds [3].

Table 2. Antimicrobial activity results of naringin (MICs in $\mu \mathrm{g} / \mathrm{mL}$ )

\begin{tabular}{|c|c|c|c|c|}
\hline & E. coli & S. aureus & L. monocyt & C. albicans \\
\hline Naringin & 500 & 31.2 & 250 & 500 \\
\hline Amoxicillin & 0.5 & $\leq 0.125$ & 0.5 & \\
\hline Ketoconazole & & & & 0.25 \\
\hline
\end{tabular}

It was reported that Naringin inhibited Actinomyces naeslundii, Actinomyces viscosus, Aggregatibacter actinomycecomitans, Enterococcus faecalis, E. coli, S. aureus, Lactobacillus casei, and 
C. albicans [23]. The mechanisms behind a possible antimicrobial effect of naringin are virtually unknown. However, it has been suggested that the antibacterial activity was related to the presence of the hydroxyl side groups [24].

\section{Cytotoxicity results}

For the in vitro cytotoxicity study, the direct contact test was chosen among the methods recommended by ISO [15] while the formulation's ability to cause irritation was tested using HETCAM [25]. In this study, the cytotoxicity of naringin gel was evaluated on L929 fibroblast cell lines by direct contact assay after treatment with Naringin gel for $24 \mathrm{~h}$. The percentage viability of the negative control group was considered $100 \%$. As it is seen in the Figure 2, the naringin gel did not show any cytotoxic effect on L929 cells. According to the study by Auner et al. which investigate the antioxidant activity and cytotoxicity of naringin, there was no strong cytotoxic effect detected demonstrating that naringin is non-toxic [26]. Similarly, Fan et al. measured the cell viability of free naringin on KB cells and no cytotoxicity was observed [27].

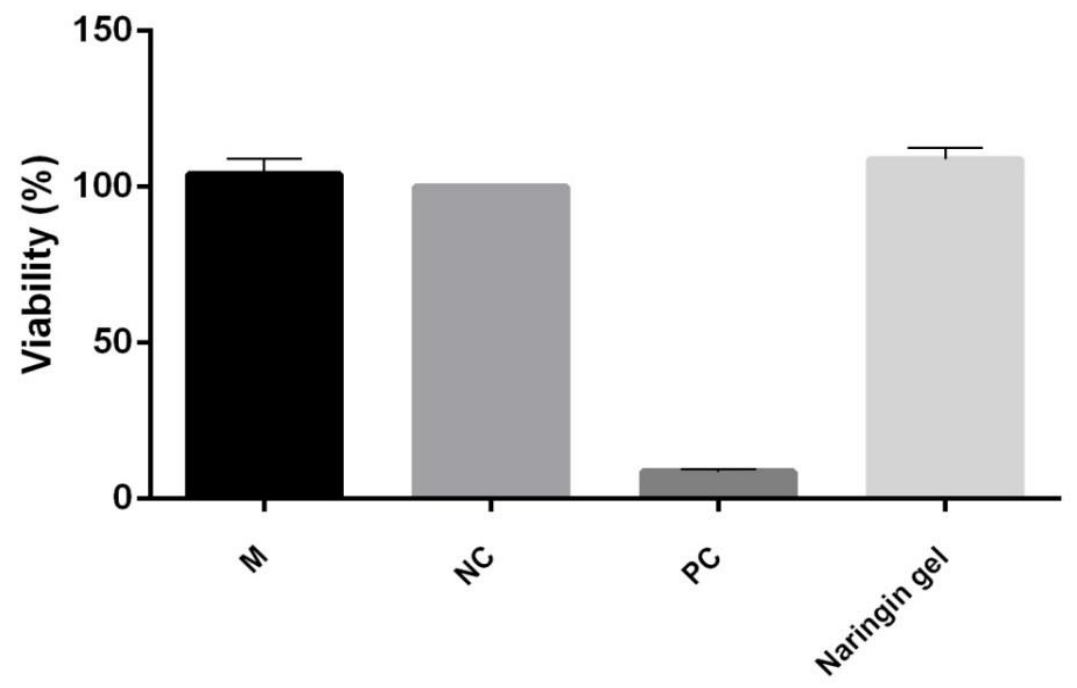

Figure 2. Effect of Naringin gel on L929 cell viability. Cells were treated with naringin gel for $24 \mathrm{~h}$. M: Medium control, NC: Negative control (PBS), PC: Positive control (4\% SDS). Statistical significances were indicated for each compound vs $\mathrm{NC}(* p<0.05)$.

\section{HET-CAM}

ICCVAM recommends the HET-CAM method as a highly preferred test for the prediction of eye injury hazard potential of chemicals, despite being not validated yet [28]. It is considered a more sensitive method due to chorioallantoic membrane's property of being thinner than mucous membranes 
of the eye [29]. Even though the method is used for the testing of ocular irritation potential, it is also suggested for the skin irritation with a similar level of efficacy, comparably [25].

In the HET-CAM test method, $0.3 \mathrm{~mL}$ of $\mathrm{NC}, \mathrm{PC}$, naringin gel, and blank gel were directly applied to the CAM surface after removal of the inner membrane. The responses on the CAM surface were observed and scored over a period of 300 seconds with intervals of $0.5,2$, and 5 minutes. The results are given in Table 3 .

Table 3. Irritation score of formulations according to HET-CAM protocol.

\begin{tabular}{|c|c|c|}
\hline Tested Substance & IS Score & Result \\
\hline NC & 0 & No irritation potential \\
\hline PC & 17 & Strong irritation potential \\
\hline Blank gel & 0 & No irritation potential \\
\hline Naringin gel & 0 & No irritation potential \\
\hline
\end{tabular}

NC: negative control $(0.9 \% \mathrm{NaCl})$; PC: positive control $(0.1 \mathrm{~N} \mathrm{NaOH})$

According to the IS analysis method, a value greater than 9 indicates the severe irritancy potential of a substance. As s stated by the results, the IS value of $\mathrm{NC}(0.9 \% \mathrm{NaCl})$ was scored as 0 , and PC $(0.1$ $\mathrm{N} \mathrm{NaOH}$ ) was scored as 17 . These results are considered within an acceptable range as stated in the ICCVAM protocol. Blank gel and the analyzed substance naringin gel did not induce lysis, hemorrhage, and coagulation therefore classified as non-irritant according to HET-CAM scoring (Figure 3).

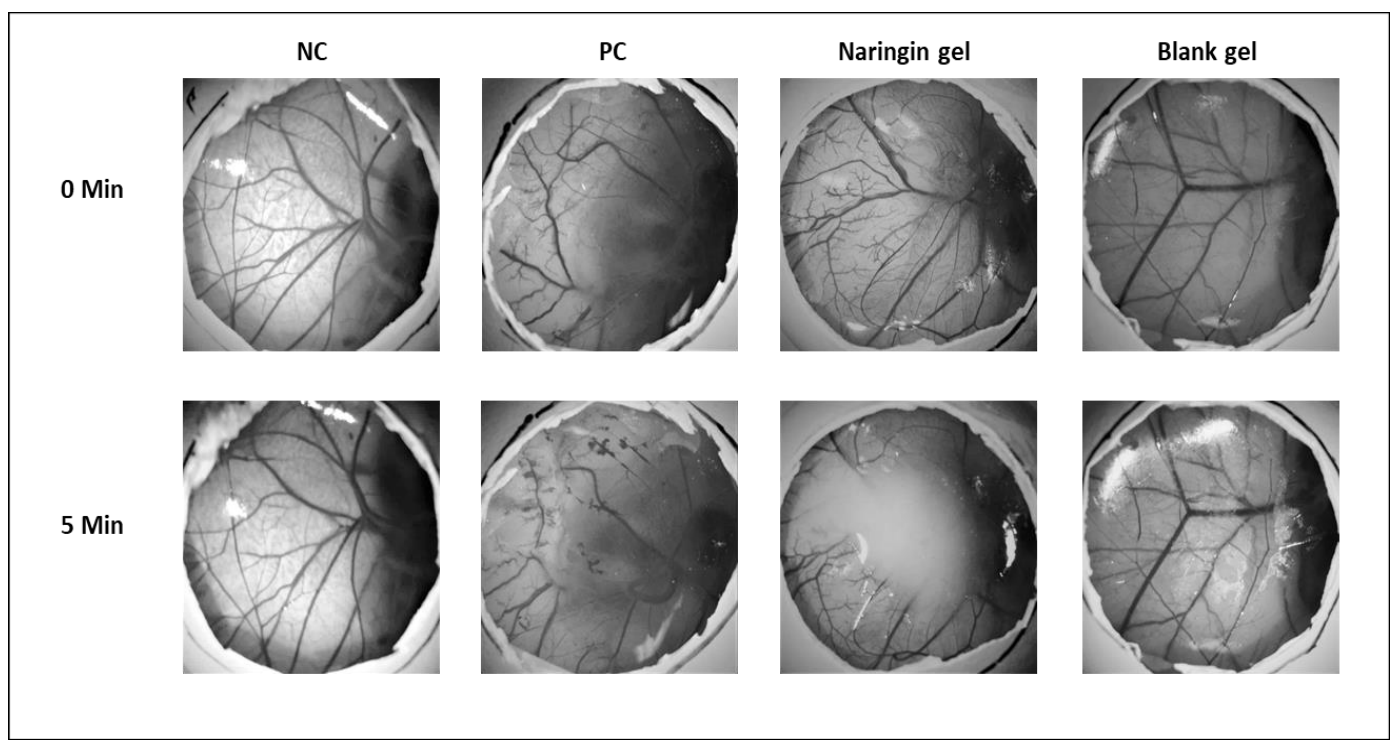

Figure 3. Macroscopic illustration of the HET-CAM test among NC (negative control), PC (positive control), Naringin gel, Blank gel groups before applying the samples, and after $5 \mathrm{~min}$. 


\section{In vivo Experiments}

\section{Macroscopic wound healing and wound contraction}

Excision wounds are used to study the rate of wound contraction and epithelialization [30]. Wound shrinkage in the early period of the healing process, granulation tissue formation, and reepithelialization are crucial for wound closure [8]. Topically administered drugs are effective for faster wound contraction because of the larger availability at the wound site [31].

The macroscopic changes of the wound area in the different groups over a period of 10 days are presented in Figure 4. A crust forming was detected on the lesion area after a few days. A residual lesion was felt on the skin after the crust fell off. It was also observed that naringin and blank gel treatments show no dermal irritation or any allergic skin reaction.

The rate of wound closure was calculated as the percentage of wound reduction from the original wound on the $5^{\text {th }}$, and $10^{\text {th }}$ days to estimate the wound repair ability of treatments in diabetic mice (Figure 5). The quantitative measurements of wound size are routinely used to assess initial wound size before and after debridement, as well as progress towards wound closure [32]. Naringin and Madecassol displayed a considerably improved wound healing on day $6(p<0.001)$, and $10(p<0.001)$ in comparison with control.

The healing percentage of scar tissue surface area ranged from $42.05 \%$ to $25.29 \%$ in the control group, $40.31 \%$ to $22.48 \%$ in blank gel group, $24.25 \%$ to $16.18 \%$ in madecassol group, and $31.85 \%$ to $17.57 \%$ in naringin group in the period from 6 to 10 days. Scars treated with Madecassol and naringin recovered quickly and the wound area rapidly decreased in size by the $10^{\text {th }}$ day compared to the control group.

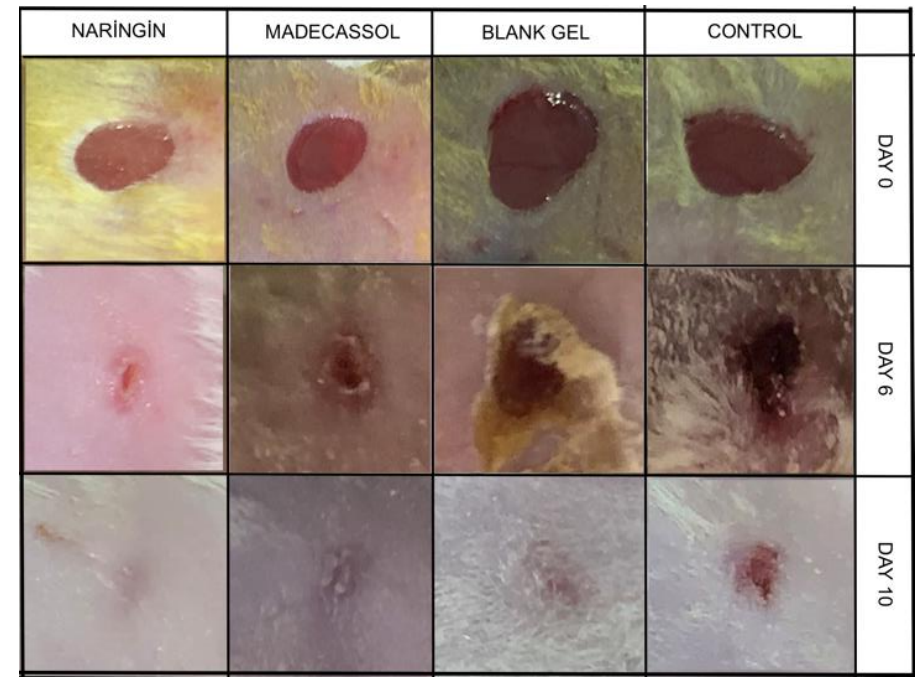

Figure 4. Effects of treatments on wound contraction. Photographic representation of contraction rate on different days of groups. 


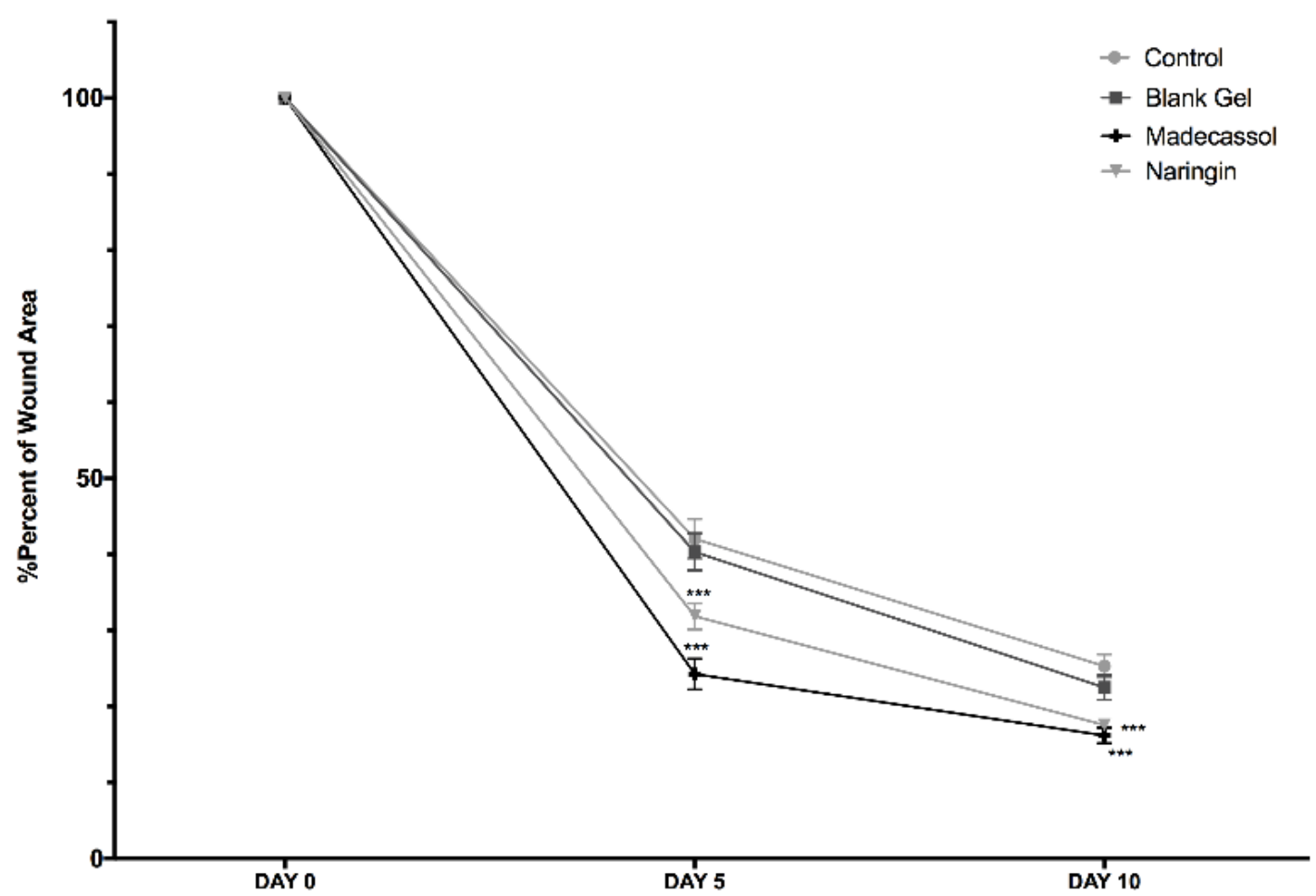

Figure 5. The healing rates of wound area among groups on days 0-10. Each data point represents the mean \pm SEM.

Fibroblast performs a key position in the wound contraction in consequence of activation of collagen formation. It was revealed that topical naringin (4\%) application improves wound healing in normoglycemic rats which could be due to the increased proliferation of fibroblasts [8].

\section{Histology}

The wound healing process consists of different phases such as granulation, collagenization, collagen maturation and scar maturation, which are concurrent but independent to each other [7]. Phases of the diabetic wound could be trapped in either of the phases for a longer time and also vanish the model synchrony of cascade that causes rapid healing [2]. The microscopic images captured during the histological analysis of the wound tissues on the $10^{\text {th }}$ day are illustrated in Figure 6. 


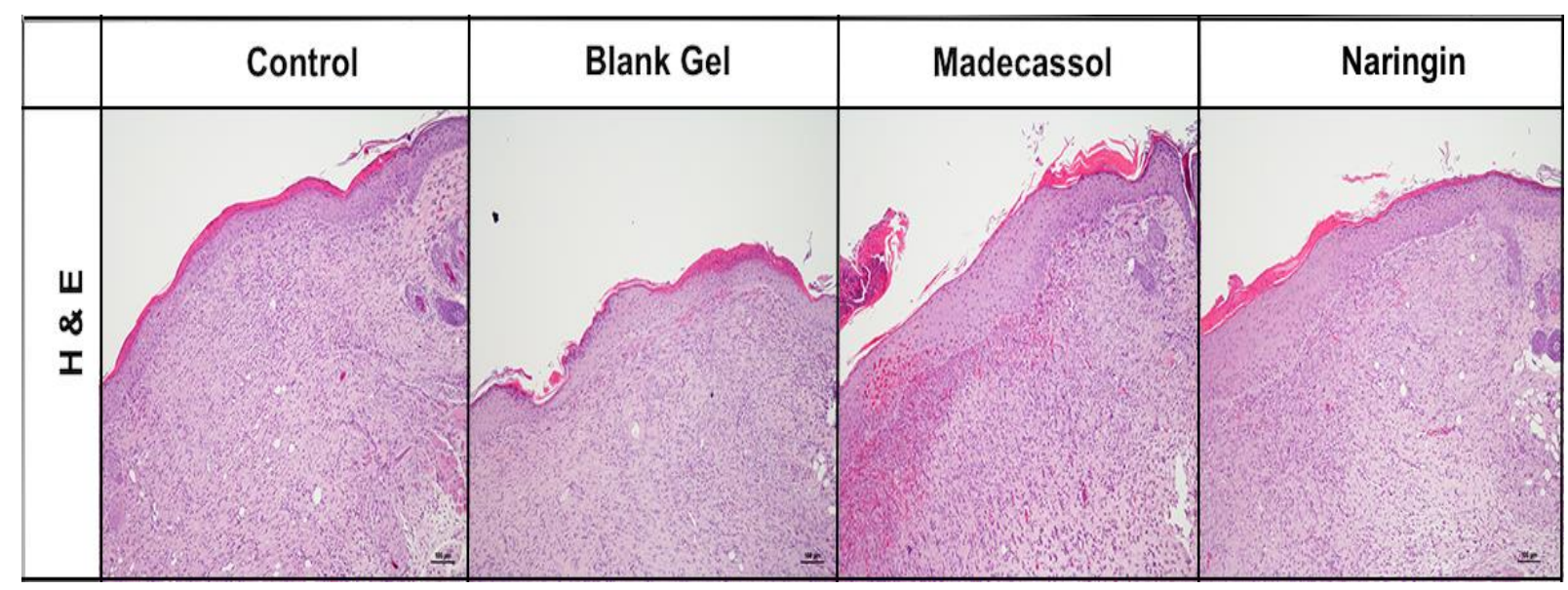

Figure 6. Histological examination of healed wound sections stained with H\&E. The photomicrographs show healed wound sections isolated from mice treated with madecassol, blank, and naringin gel on day 10 after wounding.

Angiogenesis performed a key function in the matrix composition during the wound healing process. It included the development of endothelial cells involving neutrophils, macrophages, thrombocytes, keratinocytes, macrophages, and fibroblasts from main blood vessels, followed by migration, proliferation, and anastomosis to other vessels [12]. Histological outcomes revealed that there were significantly more blood vessel formations with the madecassol $(p<0.001)$ and naringin $(p<0.001)$ as compared to the control group (Figure 7).

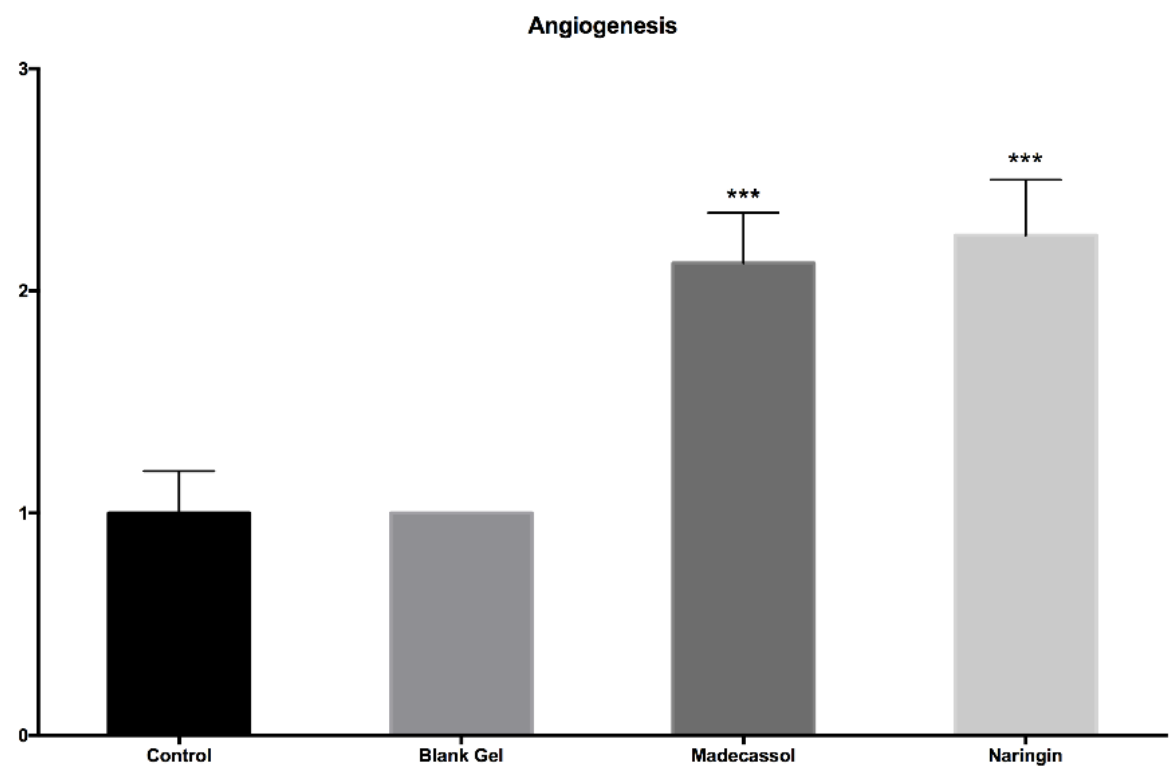

Figure 7. Microscopic assessment of angiogenesis among groups by histological scores. Significant to control; $\mathrm{p}<0.001(* * *)$ 
It was reported that Naringin treatment showed promising wound healing ability by decreasing the expression of inflammatory cytokines such as TNF-a, IL-1b, IL-8, and IL-6 and apoptotic mediators along with the increased expression of growth factors such as VEGF and TGF-b, hence modulating collagen-1 gene expression to induce angiogenesis leading to wound healing [12]. It was also reported that naringin depressed the STZ-induced raised blood glucose concentration, enhanced antioxidant capacity, decreased expression of inflammatory cytokines such as TNF-a, IL-6, IL-1b and increased the expression of growth factors such as TGF-b1, VEGF-c, IFG-1, therefore, induced angiogenesis leading to less delay in healing of chronic diabetic ulcers [8].

Granulation

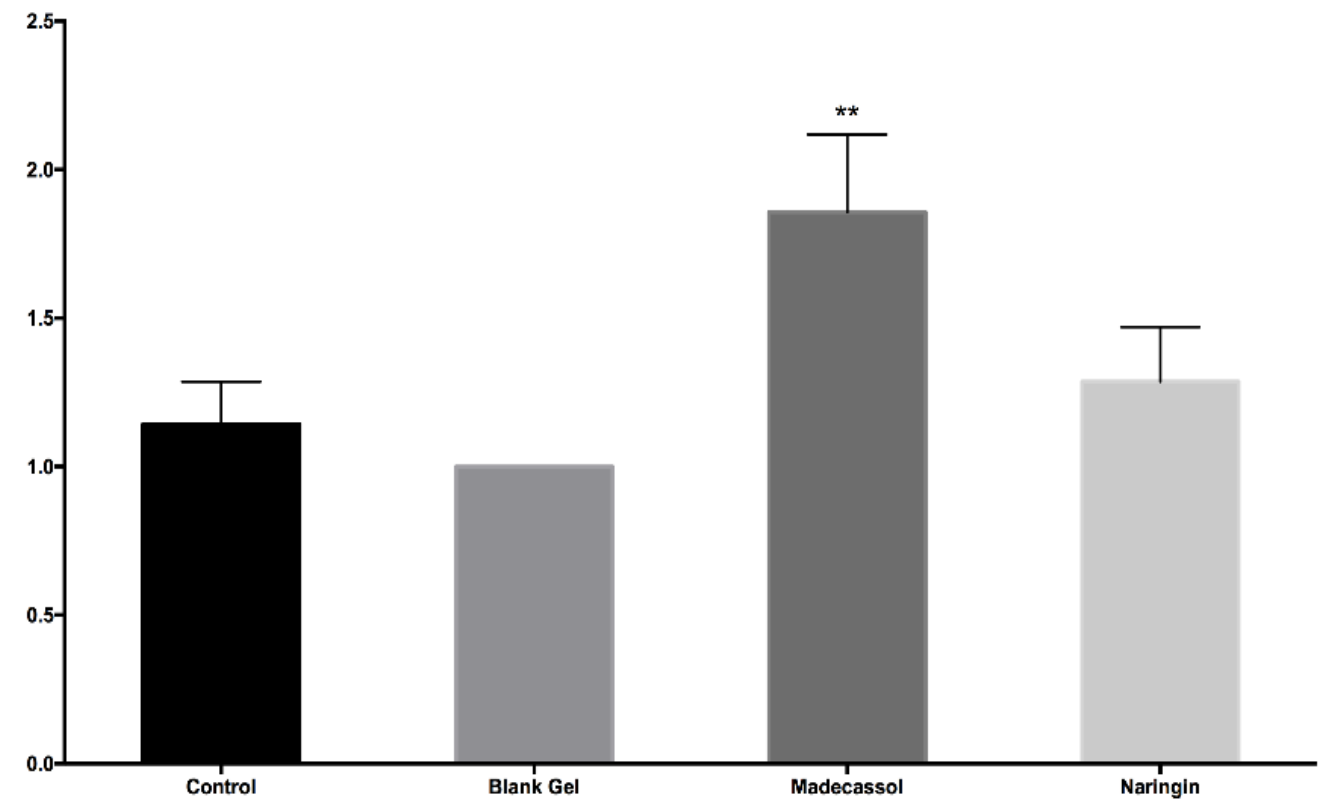

Figure 8. Microscopic assessment of granulation tissue thickness among groups by histological scores. Significant to control; $\mathrm{p}<0.01(* *)$

Diabetic wounds exhibit a persistent inflammatory phase associated with an impediment in the formation of mature granulation tissue and a reduction in wound tensile strength. This could be due to vascular damage resulting in ischemia [33]. According to the results obtained from the tissue samples; it was determined that madecassol $(p<0.01)$ had a significant effect compared to the control group. In addition, it was observed that thicker granulation tissue was formed in the naringin group compared to the control after treatment (Figure 8).

The granulation tissue formation, dermis, and epidermis thickness are all closely related to the healing course. The granulation layer is initially formed from the base of the wound. Granulation tissue 
additionally supports a matrix utilized by keratinocytes to migrate along which activates reepithelialization from the wound edges [34].

Epidermal and dermal regeneration

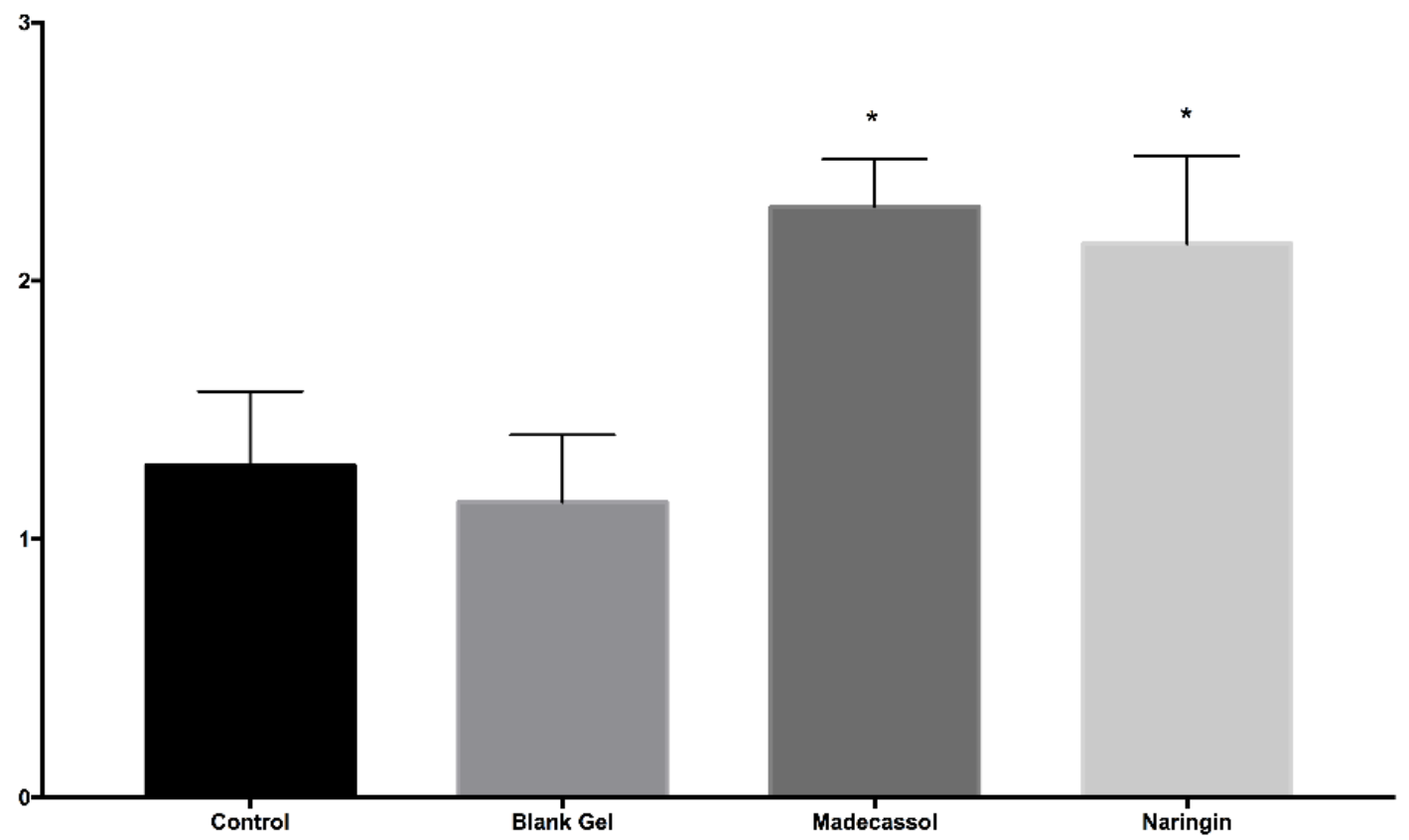

Figure 9. Microscopic assessment of epidermal-dermal regeneration among groups by histological scores. Significant to control; $\mathrm{p}<0.05\left(^{*}\right)$

Madecassol $(p<0.05)$ and Naringin $(p<0.05)$ groups showed significant dermal and epidermal regeneration scores in comparison to the control group (Fig. 9). Similarly, in a previous study which was conducted by Kandhare et al., it was shown that daily Naringin ( 20,40 and $80 \mathrm{mg} / \mathrm{kg}$, p.o.) treatment was able to shorten foot ulcer healing time in diabetic rats [8].

In conclusion, the present study displayed that the Naringin gel did not cause lysis, hemorrhage, coagulation, and also did not possess cytotoxic activity, according to the irritation (HET-CAM) and cytotoxicity test results. Besides these, in vitro antimicrobial test revealed that Naringin exhibited weak antimicrobial activity. The data obtained from in vivo study demonstrated that naringin ameliorated wound closure and re-epithelization, enhanced granulation tissue formation, and improved epidermal regeneration in a diabetic wound model. In the current study, the topical administration of naringin gel was capable of effectively stimulating the wound healing process.

\section{CONFLICT OF INTEREST}

The authors declare no conflict of interest. 


\section{REFERENCES}

1. Okur, M.E., Karantas, I.D., Siafaka, P.I. (2017). Diabetes Mellitus: A Review on Pathophysiology, Current Status of Oral Pathophysiology, Current Status of Oral Medications and Future Perspectives. Acta Pharmaceutica Sciencia, 55, 61.

2. Shah, S.A., Sohail, M., Khan, S., Minhas, M.U., de Matas, M., Sikstone, V., Hussain Z., Abbasi M., Kousar M.et al. (2019). Biopolymer-based biomaterials for accelerated diabetic wound healing: A critical review. International Journal of Biological Macromolecules, 139, 975-993.

3. Siafaka, P.I., Zisi, A.P., Exindari, M.K., Karantas, I.D., Bikiaris, D.N. (2016). Porous dressings of modified chitosan with poly(2-hydroxyethyl acrylate) for topical wound delivery of levofloxacin. Carbohydrate Polymers, 143, 90-99.

4. Veith, A.P., Henderson, K., Spencer, A., Sligar, A.D., Baker, A.B. (2019). Therapeutic strategies for enhancing angiogenesis in wound healing. Advanced Drug Delivery Reviews, 146, 97-125.

5. Okur, M.E., Karantas, I.D., Şenyiğit, Z., Okur, N.Ü., Siafaka, P.I. (2020). Recent trends on wound management; new therapeutic choices based on polymeric carriers. Asian Journal of Pharmaceutical Sciences, January 23, 2020

6. Rao, S.S., Venkatesan, J., Prabhu, A., Rekha, P.D. (2020). Natural polymeric biomaterials in growth factor delivery for treating diabetic foot ulcers. Journal of Drug Delivery Science and Technology, 55, 101385.

7. Cho, H., Blatchley, M.R., Duh, E.J., Gerecht, S. (2019). Acellular and cellular approaches to improve diabetic wound healing. Advanced Drug Delivery Reviews, 146, 267-288.

8. Kandhare, A.D., Ghosh, P., Bodhankar, S.L. (2014). Naringin, a flavanone glycoside, promotes angiogenesis and inhibits endothelial apoptosis through modulation of inflammatory and growth factor expression in diabetic foot ulcer in rats. Chemico-Biological Interactions, 219, 101-112.

9. Gadelkarim, M., Abushouk, A.I., Ghanem, E., Hamaad, A.M., Saad, A.M. and Abdel-Daim, M.M. (2018). Adipose-derived stem cells: Effectiveness and advances in delivery in diabetic wound healing. Biomedicine and Pharmacotherapy, 107, 625-633.

10. Ahmed, O.M., Mohamed, T., Moustafa, H., Hamdy, H., Ahmed, R.R. and Aboud, E. (2018). Quercetin and low level laser therapy promote wound healing process in diabetic rats via structural reorganization and modulatory effects on inflammation and oxidative stress. Biomedicine and Pharmacotherapy, 101, 58-73.

11. Özay, Y., Güzel, S., Yumrutaş, Ö., Pehlivanoğlu, B., Erdoğdu, İ.H., Yildirim, Z., Türk, B.A., Darcan, S. (2019). Wound healing effect of kaempferol in diabetic and nondiabetic rats. Journal of Surgical Research, 233, 284-296.

12. Kandhare, A.D., Alam, J., Patil, M.V.K., Sinha, A. and Bodhankar, S.L. (2016). Wound healing potential of naringin ointment formulation via regulating the expression of inflammatory, apoptotic and growth mediators in experimental rats. Pharmaceutical Biology, 54, 419-432.

13. Karadağ, A.E., Demirci, B., Çaşkurlu, A., Demirci, F., Okur, M.E., Orak, D., Sipahi, H., Başer, K. H. C. (2019). In vitro antibacterial, antioxidant, anti-inflammatory and analgesic evaluation of Rosmarinus officinalis L. flower extract fractions. South African Journal of Botany, 125, 214-220. 
14. Siafaka, P., Okur, M.E., Ayla, Ş., Er, S., Cağlar, E.Ş. (2019). Design and characterization of nanocarriers loaded with Levofloxacin for enhanced antimicrobial activity; physicochemical properties , in vitro release and oral acute toxicity. Brazilian Journal of Pharmaceutical Sciences, $55,1-13$.

15. Standardization, C.-E.C. for (2009). ISO 10993-5:2009 - Biological evaluation of medical devicesPart 5: Tests for in vitro cytotoxicity. https://www.iso.org/standard/36406.html (21 April 2020).

16. Üstündağ Okur, N., Filippousi, M., Okur, M.E., Ayla, Ş., Çağlar, E.Ş., Yoltaş, A., Siafaka, P.I. (2018). A novel approach for skin infections: Controlled release topical mats of poly(lactic acid)/poly(ethylene succinate) blends containing Voriconazole. Journal of Drug Delivery Science and Technology, 46, 74-86.

17. HET-CAM (2010). ICCVAM-Recommended Test Method Protocol: Hen's Egg TestChorioallantoic Membrane (HET-CAM) Test Method.

18. Okur, M.E., Polat, D.C., Ozbek, H., Yilmaz, S., Yoltas, A., Arslan, R. (2018). Evaluation of the antidiabetic property of capparis ovata desf. Var. Paleastina zoh. Extracts using in vivo and in vitro approaches. Endocrine, Metabolic \& Immune Disorders - Drug Targets, 18, 489-501.

19. Okur, M.E., Ayla, Ş., Çiçek Polat, D., Günal, M.Y., Yoltaş, A. and Biçeroğlu, Ö. (2018). Novel insight into wound healing properties of methanol extract of Capparis ovata Desf. var. palaestina Zohary fruits. Journal of Pharmacy and Pharmacology, 70, 1401-1413.

20. Galeano, M., Altavilla, D., Bitto, A., Minutoli, L., Calò, M., Cascio, P. Lo, et al. (2006). Recombinant human erythropoietin improves angiogenesis and wound healing in experimental burn wounds*. Critical Care Medicine, 34, 1139-1146.

21. Özçelik, B., Kartal, M., Orhan, I. (2011). Cytotoxicity, antiviral and antimicrobial activities of alkaloids, flavonoids, and phenolic acids. Pharmaceutical Biology, 49, 396-402.

22. Budovsky, A., Yarmolinsky, L., Ben-Shabat, S. (2015). Effect of medicinal plants on wound healing. Wound Repair and Regeneration, 23, 171-183.

23. Gutiérrez-Venegas, G., Gómez-Mora, J.A., Meraz-Rodríguez, M.A., Flores-Sánchez, M.A., OrtizMiranda, L.F. (2019). Effect of flavonoids on antimicrobial activity of microorganisms present in dental plaque. Heliyon, 5(12), e03013.

24. Jang, M.H., Piao, X.L., Kim, J.M., Kwon, S.W., Park, J.H. (2008). Inhibition of cholinesterase and amyloid-\&bgr; aggregation by resveratrol oligomers from Vitis amurensis. Phytotherapy Research, 22, 544-549.

25. Ishaka, A., Ismail, M., Imam, M.U., Mahmud, R., Sani, I.M., Zakaria, Z.A.B. (2017). Toxicity Evaluation, HET-CAM Irritation, and Anti-Irritant Potential of Rice Bran Wax Policosanol Nanoemulsion. Journal of Nano Research, 49, 44-55.

26. Auner, B.G., Wirth, M., Valenta, C. (2005). Antioxidative activity and cytotoxicity of four different flavonoids for dermal applications. Journal of Drug Delivery Science and Technology, $15,227-232$.

27. Fan, H., Zhang, P., Zhou, L., Mo, F., Jin, Z., Ma, J., Lin, R., Liu, Y., Zhang J. (2020). Naringinloaded polymeric micelles as buccal tablets: formulation, characterization, in vitro release, 
cytotoxicity and histopathology studies. Pharmaceutical Development and Technology, 25(5),547555 .

28. Sipahi, H., Reis, R., Dinc, O., Kavaz, T., Dimoglo, A., Aydın, A. (2019). In vitro biocompatibility study approaches to evaluate the safety profile of electrolyzed water for skin and eye. Human and Experimental Toxicology, 38, 1314-1326.

29. Dahl, J.E. (1999). Irritation of dental adhesive agents evaluated by the HET-CAM test. Toxicology in Vitro, 13, 259-264.

30. Liu, W.Y., Tzeng, T.F., Liu, I.M. (2017). Healing potential of zerumbone ointment on experimental full-thickness excision cutaneous wounds in rat. Journal of Tissue Viability, 26, 202207.

31. Suriyamoorthy, S., Subramaniam, K., Jeevan Raj Durai, S., Wahaab, F., Pemila Edith Chitraselvi, R. (2014). Evaluation of wound healing activity of Acacia caesia in rats. Wound Medicine, 7, 1-7.

32. Abu-Al-Basal, M.A. (2010). Healing potential of Rosmarinus officinalis L. on full-thickness excision cutaneous wounds in alloxan-induced-diabetic BALB/c mice. Journal of Ethnopharmacology, 131, 443-450.

33. Patel, S., Srivastava, S., Singh, M.R., Singh, D. (2019). Mechanistic insight into diabetic wounds: Pathogenesis, molecular targets and treatment strategies to pace wound healing. Biomedicine and Pharmacotherapy, 112, 108615.

34. Devalliere, J., Dooley, K., Yu, Y., Kelangi, S.S., Uygun, B.E., Yarmush, M.L. (2017). Co-delivery of a growth factor and a tissue-protective molecule using elastin biopolymers accelerates wound healing in diabetic mice. Biomaterials, 141, 149-160. 